\title{
Intramural haematoma of the oesophagus complicating sclerotherapy for varices
}

\author{
F Mosimann, B Brönnimann
}

Department of Surgery, University Hospital CHUV Lausanne, Switzerland

F Mosimann

B Brönnimann

Correspondence to:

Dr F Mosimann, Department of Surgery, University Hospital - CHUV, 101 Lausanne, Switzerland.

Accepted for publication 8 April 1993

\begin{abstract}
A patient is described who developed an intramural haematoma of the oesophagus shortly after variceal endoscopic sclerotherapy. This unusual complication is best imaged by computed tomography or nuclear magnetic resonance and needs conservative treatment. Resolution usually occurs spontaneously and may result in eradication of the varices.
\end{abstract}

(Gut 1994; 35: 130-131)

Endoscopic sclerotherapy is the cornerstone for both acute and elective management of bleeding oesophageal varices. Complications occur, however, in up to $46 \%$ of patients and the procedure related mortality is about $1-2 \%{ }^{1}$ This report describes an intramural haematoma of the oesophagus, a rare but potentially dangerous complication of variceal injection.

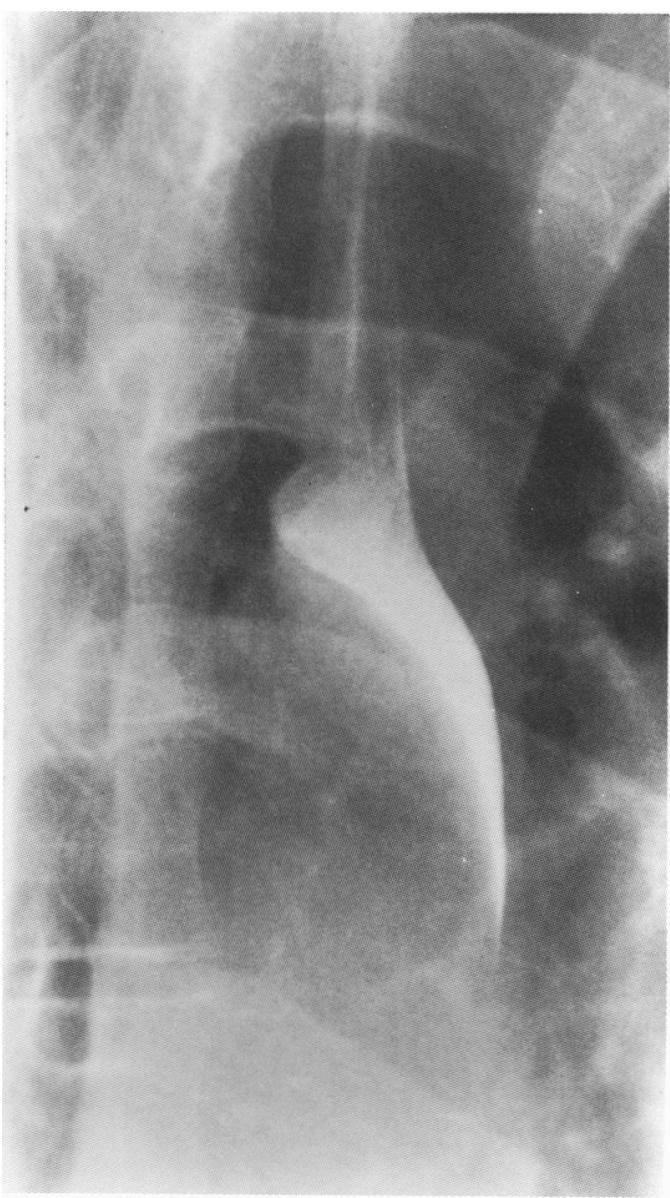

\section{Case report}

A 52 year old man suffered a variceal bleed secondary to posthepatitis $\mathrm{C}$ cirrhosis. This was treated by emergency sclerotherapy, using a technique of both intra and paravariceal injections of $1 \%$ polidocanol. The patient was then enrolled into a programme of elective longterm prophylactic sclerotherapy. Four months later, 24 hours after his fifth outpatient endoscopy session, he complained of retrosternal pain. Within a few hours, he also developed total dysphagia. A Gastrografin swallow showed an occlusion of the distal oesophagus (Fig 1). Computed tomography showed an intramural soft tissue mass compressing the lumen of the lower third (Fig $2 \mathrm{~A}$ ) resulting in occlusion (2B; $2 \mathrm{~cm}$ below Fig $2 \mathrm{~A}$ ).

An oesophageal tube was placed just above the obstacle under fluoroscopic guidance to drain the saliva. Total parenteral nutrition and drugs were given. One week later, another contrast swallow showed the reopening of the lumen and oral intake was therefore gradually resumed. At endoscopy five weeks later, the varices were eradicated and the patient had no further oesophageal complaints. Liver transplantation was performed successfully one year later.

\section{Discussion}

Intramural haematoma of the oesophagus is rare. It may be spontaneous or can be induced by a Mallory-Weiss tear, instrument trauma, anticoagulant treatment, and haematologic malignancies. ${ }^{2}$ After endoscopic sclerotherapy, an incidence of 0.3 to $1.6 \%$ has been reported ${ }^{13}$ and our case is the only one of a series of 259 consecutive patients who received a total of 1867 injections between 1981 and 1992. Tissue necrosis extending into the submucosa and muscularis is probably the initial pathogenic event. An abnormal coagulation profile and raised portal pressure then tend to enhance longitudinal and circumferential expansion, resulting in submucosal dissection. ${ }^{4}$

Although pain and dysphagia suggest the diagnosis of intramural haematoma, symptoms may be mistaken for an oesophageal perforation, a myocardial infarct, or a dissecting aortic aneurysm. We feel therefore that imaging techniques are required in this situation. A water soluble contrast swallow seems an excellent screening tool to rule out an oesophageal perforation. ${ }^{34}$ The nature of the obstructive lesion is, however, better defined by computed tomo- 

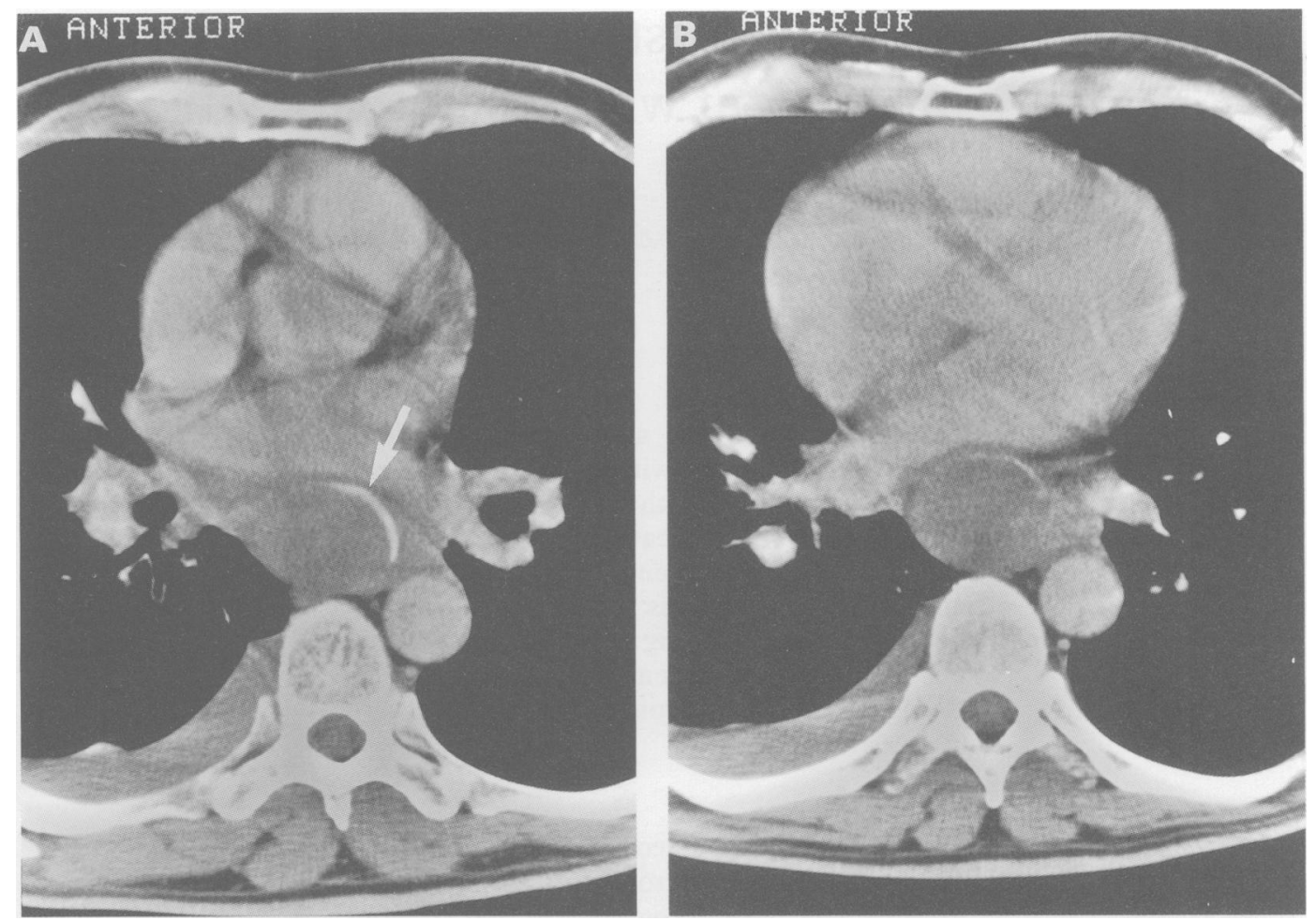

Figure 2: Computed tomography after barium swallow: $(A)$ compression of the oesophageal lumen by an intramural haematoma of the lower third (arrow); $(B)$ occlusion of the lumen, $2 \mathrm{~cm}$ lower than $(A)$.

graphy ${ }^{5}$ or nuclear magnetic resonance, ${ }^{6}$ showing a hyperdense mass without enhancement after intravenous contrast injection. We do not agree with others, ${ }^{37}$ who recommend endoscopy, as it carries a risk of life threatening iatrogenic perforation. ${ }^{8}$

Because spontaneous rupture of the haematoma is rare, treatment should be conservative, resulting in complete recovery in two to three weeks. Submucosal healing and scarring may even contribute to the eradication of the varices, as in our patient.

1 Kahn D, Jones B, Bornman PC, Terblanche J. Incidence and management of complications after injection sclerotherapy: A ten-year prospective evaluation. Surgery 1989; 105: 160-5.
2 Hanson JM, Neilson D, Pettit SH. Intramural oesophageal dissection. Thorax 1991; 46: 524-7.

Desmorat H, Cales P, Vinel JP, Magnin P, Cancanas JP, Combis JM, et al. Hématome intramural obstructif de 'oesophage. Gastroenterol Clin Biol 1990; 14: 581-5.

4 Low DE, Patterson DJ. Complete esophageal obstruction secondary to dissecting intramural hematoma after endoscopic variceal sclerotherapy. Am $\mathcal{F}$ Gastroenterol 1988; 83: 435-8.

5 McGrath JP, Walsh TN, Hennessy TPJ. Total dysphagia from intramural haematoma following sclerotherapy for oesophageal varices. Brf Surg 1992; 79: 781.

6 Boyer L, Pezet D, Boissier A, Naamee A, Michel JL, Escande G. Hématome intra-mural de l'oesophage. Intérêt de l'imagerie par résonnance magnétique. Gastroenterol Clin Biol 1992;16: 482-3.

7 Jones DB, Frost RA, Goodacre RL. Intramural hematoma of the oesophagus. A complication of endoscopic injection sclerotherapy. Gastrointest Endosc 1986; 32: 239-40.

8 Skillington PD, Matar KS, Gardner MA, Parkes RP, Cale PH. Intramural haematoma of the oesophagus complicated by perforation. Aust N Z F Surg 1989; 59: 430-2. 